\title{
ANALYSIS OF VISION AND MISSION STATEMENTS CHARACTERISTICS AND THEIR ASSOCIATION WITH ORGANIZATIONAL PERFORMANCE: A GUIDE TO WRITING EFFECTIVE VISION AND MISSION STATEMENTS
}

\author{
Forest David \\ University of Debrecen, Faculty of Economics and Business, 4002. Pf. 400 \\ david.forest@econ.unideb.hu
}

\begin{abstract}
This paper empirically examines vision and mission statements of Fortune 500 firms for the purpose of identifying and examining specific characteristics and associating these attributes with organizational performance. Additionally, this paper provides a theoretical foundation for the inclusion of various characteristics of vision and mission documents, and thus provides guidance for organizations to develop and revise these important strategic planning documents.
\end{abstract}

Keywords: vision-mission, strategic planning, organizational performance

(JEL Classification: M21, O21)

\section{INTRODUCTION}

Peter Drucker, known to many around the world as the father of modern management, was a proponent of organizations having formally written vision and mission statements. Drucker (1974) proposed early in his career that firms should ask three questions before engaging in strategy or any other formal aspects of planning: 1) Where are we going? 2) What business are we in? 3) How are we going to get there? Question 1 above is similar to the commonly used definition of a vision statement often stated as "what do we wish to become" and Question 2 is the currently universally accepted definition of mission. Question 3 by Drucker addresses the strategy and tactics used to execute both the vision and mission statements. Drucker's thoughts on firms having formal vision and mission statements, much like other aspects of his work, are articulated beautifully simple yet vitally important for success and survival in business today just as they were two generations ago during Drucker's time.

Increasingly today there is a growing need for organizations whether a Fortune 500 firm, a mom and pop business, a university, or a not-for-profit firm to have a clear vision and mission statement as the precursor to a detailed strategic plan. With the current climate of globalization, rapid transfer of information, and technological advancements, many mistakenly believe there is less need for a clear vision and mission as firms strive to adapt to survive. As firms are required to adapt more quickly now than ever before since customers are increasingly more demanding and discriminating in their purchasing habits. The latter forces firms to have a clear vision, mission and strategy.

This paper further develops the vision and mission statement literature and set up a series of hypotheses for empirically testing the characteristics of vision statements and mission statements. Additionally this paper will attempt to relate vision and mission statement attributes to firm performance; the main objective is to determine a set of vision and mission characteristics common among firms Specifically in this paper, 74 vision and 74 mission statements included in the most recent Fortune 500 list are critiqued in accordance with methodology set forth and statistical results will be tabulated.

Although there have been multiple papers studying mission statements components or their association to organizational performance whether it be direct financial measures or indirect customer satisfaction measures or employee responses 
on a survey, there has been little research on vision statements. Also, to our knowledge, there has been little to no prior research on mission and vision characteristics. We define characteristics more broadly than components.

This paper attempts to address this shortcoming in the literature and provide a foundation for future vision statement research, provide a framework for writing mission and vision statements using characteristics commonly found in Fortune 500 firms' statements, and to examine the link on organizational performance and mission / vision quality from a characteristic perspective, which has not been previously addressed in the literature to our knowledge.

\section{Literature Review}

Today there are virtually limitless choices no matter the industry. For example with automobiles, customers now can purchase cars with almost unlimited features all tailored to specific customer needs. Similarly in the cosmetic industry there are virtually limitless choices, as is also true in the restaurant industry and countless other areas of business. The days of producing a product that will satisfy the needs of a large percentage of the population are vanishing. These new trends in customer preferences and demands is increasingly forcing organizations to have a clear, detailed, well conceived vision, mission and strategy.

Vision and mission development continues to be considered an important first step in strategic planning and several textbooks even devote a full chapter just to vision and mission statements.

A study by Alegre, et al., (2018) revealed mission statement articles in 20 different academic journals totaled to 53 from 1980 to 2014 with the largest number the five year period from 1995 to 1999 with 14 articles. The most recent five year period 2010 to 2014 had 8 such papers and the first period of 1980 to 1984 only had 2 papers written within the 20 journals studied revealing a steady trend of around 2 papers in the 20 academic journals studied related to mission per year since 1990. Of the publications studied, over 50 percent studied the association with mission and organizational performance, followed by researching mission statement components, impact on employees, and development. A recent paper by David, et al., (2016) studied mission statements as related to customer satisfaction.

\section{Benefits of Quality Vision and Mission Statements}

Although debate continues regarding whether effectively written vision and mission statements will lead to improved organizational performance, a meta-analysis by Desmidt et al., (2011) indicated mixed results on firm performance. King \& Cleland (1979) indicated several intangible benefits of well written mission statements include: 1) clearly states the purpose of the organization to employees and managers, 2) prioritizes key resources both internal and external that aids in the formulation of strategies, 3) aids in allocation of resources, and 4) aids in organizing work activities around departments, segments, and divisions around a shared purpose. Another key advantage of well written mission or vision statements is they provide a means to resolve divergent views among managers in a tactful manner. For example, in a university setting faculty may have honest disagreements on the relative importance of research, teaching and service in assessing individual performance. Revisiting the firm's vision and mission statement is an effective way to diffuse such disagreements in a tactful manner.

\section{Developing Effective Vision and Mission Statements}

Discussed in detail under the respective vision and mission statement sections, there are characteristics, components, and attributes that are common within vision and mission statements. Firms should include as many managers as possible when writing vision and mission statements. Generally, firms should educate managers on what constitutes a quality vision and mission statement, remind managers of the strategy and goals of the corporation, and then ask them to develop their on respective mission and vision statements (David \& David, 2017). Upon completion, top management should collect and merge statements into a single document and continue the process until an agreed upon vision and mission are developed. If properly developed, the final product will contain statements unique to the firm (David et al., 2014), be written in a quality manner consistent with vision and mission theory, and provide a robust level of commitment to the organization as many managers participated in the process.

\section{Vision Statements}

In business, having a clear vision provides the foundation for developing a mission statement. A firm must first know where it wants to go before it can determine its strategy of how it wants to get there. Research suggests that vision statements should be short, approximately once sentence in length and include as many managers as possible in developing the statement. Jeff Weiner, CEO of LinkedIn, was recently voted the best CEO in the United States and recently stated at a conference in San Francisco the single most important attribute of being an effective leader is articulating the firm's vision as meticulously and clearly as possible to everyone at the organization. Former CEO of Colgate, Reuben Mark is another large believer in vision statements, indicating, with respect to vision, it is best to push one vision globally than many different smaller messages in various different cultures. The vision pushed should be inspiring and not focused on financial means, as according to Mark, it is difficult to motivate employees into charging the machine guns (referring to the completion and their tactics) for purely financial objectives, there must be something more palpable, more meaningful than merely financial objectives.

Generally, a well-developed and thought out vision statement will provide improved direction for the firm and its stakeholders. Overall, the literature on vision statements is not as developed or robust as the prior literature on mission statements. One of the goals of this paper is to improve the theoretical contribution by developing improved insight on vision statement construction and its association with organizational performance. 


\section{Mission Statements}

Unlike the vision statement literature, the mission statement literature is robust and well contrived in the literature lending itself for a detailed literature review and thereby supporting the foundations for new studies and insights that are rooted in previously accepted theory. Mission statements are often called by other names that include: creed statement, statement of purpose, statement of philosophy, and statement of guiding principles. Sometimes mistakenly, firms will call a mission statement by the name vision and a vision statement by the name mission. For purposes of this paper, mission statements answer the question proposed by Drucker "what business are we in" and vision statements answer the question "where do we wish to go." Drucker (1974) states the first step in a strategic plan is to answer the question "what is our business;" the answer is not as obvious as many managers believe. For example, an airline carries passengers and freight, but this does not satisfactorily answer the question what is our business. For example, what percent of freight or passengers does the airline carry? Is the airline a discount airline or more full service? Regional or International? Questions such as these more readily answer the question, what is our business and must be answered before organizational structure or future plans can be implemented (Drucker, 1974).

This goal ambiguity or more clearly mission ambiguity routinely leads various managers astray focusing on their own projects and goals rather than the larger organizational mission, often at the expense of organizational performance and employee motivation. Mission clarity has revealed a positive correlation with employee motivation (Jung \& Rainey, 2011), organizational performance, employee satisfaction and goal commitment (Jung, 2013).

\section{Mission Statement Components}

One of the seminal works in mission statement construction was published by Pearce \& David (1987) in the Academy of Management Executive. This article revealed eight components commonly found in mission statements of high performing firms. These components consisted of: customers, products $\&$ services, geographic region served, technology, concern for survival, growth and financial profitability, philosophy, core competences, concern for public image. Later work by David (1989) added a 9th component, concern for employees. The collection of data in this seminal article used the Fortune 500 firms, the same publication used in this paper.

A few published journal articles have examined mission statement components, but to our knowledge, no journal articles have examined the mission statement characteristics proposed in the David 17th edition strategic management book. Thus, a clear and needed opening exists in the literature on this issue, so we have the opportunity to make a significant contribution to strategic management in this area. The ten proposed mission statement characteristics that appear in the David textbook are as follows:

\section{Characteristics of a Mission Statement}

1.Broad in scope; does not include monetary amounts, numbers, percentages, ratios, or objectives

2.Concise; fewer than 100 words in length

3.Inspiring

4.Identifies the utility of a firm's products

5. Reveals that the firm is socially responsible

6.Reveals that the firm is environmentally responsible

7.Includes nine components: customers, products or services, markets, technology, concern for survival/growth/ profits, philosophy, distinctive competence, concern for public image, concern for employees

8.Reconciliatory; resolves divergent views among stakeholders

9.Enduring but never cast in stone

10. Attracts customers; is written from a customer perspective

Source: David 17 ${ }^{\text {th }}$ ed. textbook, p. 49.

Prior research studied the nine components to determine if they were still applicable to mission statement construction assuming possibly the institutional forces of coercive, normative and mimetic pressures (DiMaggio \& Powell, 1983) would drive mission statements of firms in similar industries to be more similar than a basket of firms in different industries (Peyrefitte \& David, 2006). This was indeed the case as a sample of firms from 3 distinct industries indicated industry membership did play a significant role in components used. The study found the components of core competencies, philosophy, and concern for public image were all included in mission statements across all industries; along with components, customers, products and services, and technology that were also statistically significant on being included in mission statements.

\section{Link to Performance}

The seminal article published in 1987 in the Academy of Management Executive by Pearce and David (1987) revealed 8 components commonly associated with mission statements. 1) Customers 2) Products and Services, 3) Geographic Markets Served, 4) Technology, 5) Commitment to Survival, Growth, and Profitability, 6) Philosophy, 7) Self Concept (today referred to as Distinctive Competence), and 8) Concern for Public Image. Several years later a 9th component, Concern for Employees was suggested (David, 1989). In their article, Pearce and David concluded three of the eight components were statistically significant with higher performing firms. Higher performer firms were firms with a profit margin in the top quartile of all responding Fortune 500 firms. These three components were: Philosophy, Self-concept, and Public Image.

There has been substantial research since attempting to link the quality of mission statements to organizational performance. A meta-analysis in 2011 that focused on twenty years of research on mission statements indicated mixed evidence of mission statements boosting performance Desmidt, et al., (2011). There is a growing thought in business that with a rapidly changing world, strategy and vision and mission are not as important as they once were. As managers 
focus increasingly on means that lead directly to performance, mission statement construction oftentimes takes a back seat and is met with less enthusiasm with managers (Baetz \& Bart, 1996). Despite research suggesting managers possibly exhibit less enthusiasm developing a mission and vision, there is evidence in many journals that show a positive correlation between well written mission statements and firm performance indicating the importance of having a formal business mission.

Researchers studying American firms, Dutch firms (Sidhu, 2003), and Japanese firms (Hirota, et al., 2010) all suggest a positive correlation between firm performance and mission statements. While other research has revealed a positive relationship between desired organizational behaviors and well constructed mission statements (Bart \& Baetz, 1998; (Bart, 1996). Bart and Baetz (1998) in fact found formally written mission statements exhibited Return on Sales significantly higher than firms with poorly written mission statements. A recent article showed a positive relationship with American Consumer Satisfaction Scores (ACSI) Scores and well written mission statements David et al., (2016 ). Germain and Cooper (1990) revealed mission statements written from a customer perspective had a positive impact on firm performance.

Despite some prior research showing a positive correlation between well crafted mission statements and organizational performance, many other papers showed no such relationship. Research on the topic has ranged from studying the relationships between profits and employee turnover Klemm et al., (1991), manager satisfaction on mission statements and firm performance. Other studies such as Vandijck et al., (2007) studied the relationship between quality written mission statements and employee behavior without significant findings. Further negative evidence on the importance of mission statements was reported where firms with and without a mission statement were compared on firm performance with no differences reported (Dharmadasa et al., 2012). One possible explanation on the inconclusive findings regarding mission statements' link to organizational performance is the lack of research using a accepted definition of mission.

Another possible reason explaining the lack of significance in having a quality mission statement and firm performance is most articles to date have not examined moderating variables' association with mission and firm performance. A paper recently published provided a series of propositions laying the groundwork for assessing management's commitment to the business mission Williams, et al., (2015). Williams provides four criteria to determine management commitment, including 1) communicating and identifying the core concepts that should be included in a mission, 2) involve as many managers as reasonably possible and from various functional areas, 3) set targets with respect to the mission, and finally to 4 ) review and revise the mission as necessary. However, despite these possible improvements and suggestions, little is provided here on implementing mission statements.
This important concept reveals the fact that despite the quality of the mission statement, if management is unwilling to adhere to the statement or struggles with implementing the statement, then simply analyzing the components or other attributes of a mission for its association with firm performance will restrict the chances of finding a positive statistical relationships.

A story told in some management circles describes an encounter between a manager and the CEO of the firm, as the manager was debating with the CEO that his new ideas could be formulated or implemented because of the firm's stated strategy. In the story the CEO asked to see the formal strategy document, crosses out the affronting passage and quipped, now we can proceed with my plans. The story, true or not, serves as example if mission statements are given such treatment then there would be difficulty in finding statistical significance. Another story illustrated in the above book, was when an employee came to his manager indicating he knows the mission of the company, he believes in the mission and he is currently with the customer but he is just not sure how to implement the mission.

\section{Hypotheses}

Hypothesis $1_{\mathrm{n}}$ : Mission statements and vision statements will contain the same number of words.

Hypothesis $1_{\mathrm{a}}$ : Mission statements and vision statements will not contain the same number of words.

Hypothesis 2 : Mission statements will not average around 100 words in length

Hypothesis 2 : Mission statements will average around 100 words in length

Hypothesis $3_{n}$ : The 4 characteristics will not be found in vision statements

Hypothesis $3_{\mathrm{a}}$ : The 4 characteristics will be found in vision statements

Hypothesis $4_{n}$ : The 4 characteristics will be not found in mission statements

Hypothesis $4_{a}$ : The 4 characteristics will be found in mission statements

Hypothesis $5_{n}$ : There will be a relationship between vision statements containing the outlined characteristics and organizational performance

Hypothesis 5: There will not be a relationship between vision statements containing the outlined characteristics and organizational performance

Hypothesis 6 : there will be a relationship between mission statements containing the outlined characteristics and organizational performance

Hypothesis $6_{n}$ : there will not be a relationship between mission statements containing the outlined characteristics and organizational performance 


\section{METHODOLOGY}

\section{Data Collection}

Mission and vision statements remain commonly used. The sample used in his analysis revealed approximately 40 percent of Fortune 500 firms having both a mission and vision statement on their website, approximately 35 percent having only a mission statement and approximately 10 percent only having a vision statement provided on their website and over 80 percent of firms having at least one of the two documents posted on their websites.

In selecting mission and vision statements to analyze, a sample of 74 was drawn from the 2019 Fortune 500 list. This sample was deemed large enough to produce ample statistical power to find statistical significance if present. In addition, using the Fortune 500 has several key benefits. Most importantly, the sample "self controls" for many outside factors as all firms included in the Fortune 500 met the publication's criteria for inclusion. Using the Fortune 500 sample ensures firms are similar in nature. Secondly, using the Fortune 500 introduces less bias than if the researchers simply chose mission and vision statements in a nonrandom manner. Finally, the use of the Fortune 500 is common among many mission statement studies including Pearce \& David (1987) and Peyrefitte (2012). Once the firms were determined through a random number generator, the researchers visited the respective websites and tabulated firms who contained a mission, vision, or both. Only firms who had both a published mission and vision were rated for this study. Previous work Peyrefitte, (2012) sent formal letters to Fortune 500 firms asking for copies of their mission statements receiving 353 replies. Pearce \& David (1987) received 218 replies to a similar inquiry but only deemed 61 responses to be a usable mission statement for analysis. With improved transparency and ready access to the Internet, we feel our approach outlined above is appropriate for sample collection. In addition, we believe our sample size of 74 is sufficient based on academically accepted sample sizes smaller Pearce \& David (1987) with 61 Peyrefitte \& David, (2006) with 57.

In attempting to determine what characteristics are common in mission and vision statements, we drew from the guidelines and suggestions provided in David et al (2020) mainstream textbook Strategic Management and our own personal review of mission and vision statements not used in the study to help determine the list of characteristics common among both vision and mission statements. We determined visions and missions each had 5 characteristics each which are provided below in detail along with the coding scheme with corresponding Cronbach's alpha coefficients calculated.

\section{Cronbach's Alpha}

There were two raters of data and George and Mallery (2003) provide the following guidelines for accessing the quality of Cronbach's alpha readings are provided in Figure 1.

Tabel 1

\begin{tabular}{|l|l|}
\hline$>0.90$ & Excellent \\
\hline $0.80-0.89$ & Good \\
\hline $0.70-0.79$ & Acceptable \\
\hline $0.60-0.69$ & Questionable \\
\hline $0.50-0.59$ & Poor \\
\hline$<0.50$ & Unacceptable \\
\hline
\end{tabular}

According to Spector (1992) an appropriately designed scale should address 4 attributes

1. Scales should contain multiple items that are able to be combined for summation.

2. Measurements between items should vary quantitatively as opposed to qualitatively.

3. There should be no right answer among the choices. For example, a multiple choice exam asking the capital of the USA, only Washington DC is the correct answer thus excluding questions with single right answers.

4. Scale items are statements where raters will provide their best judgement rating about the statement.

\section{Characteristics and Coding Scheme}

The coding scheme was selected after 1) careful study of vision and mission statements and 2) adapted from prior suggestions in the David, et al., (2020) Strategic Management textbook by Pearson. Coders discussed the coding system on a sample of mission and vision statements not used in the analysis to ensure clarity was present before proceeding with the actual coding of the sample used. A 1 to 3 rating system was used for all factors other than word count, where a raw number was utilized. The 1 to 3 coding system is common in other articles on mission statements within the literature. Note Inspiring was selected as a characteristic of both vision and mission statements for research.

\section{Vision Statement Coding Scheme}

1. 1.Clear - Identifies the traditional definition of a vision statement answering the question "what do we wish to become" In addition, the Clear characteristic should identify the firm's industry to receive a higher rating. 1) Does not address the question "what we wish to become" in any regard, the statement is simply a slogan. For example, good ethics is good business or the customer is king. 2) Makes a minimal attempt to answer the question what we wish to become but is extremely vague and could be used for many industries; for example, we wish to become the top customer service firm in the world. This statement could be used equally for McDonald's or 
Airbus. 3) Addresses what the firm wishes to become and mentions the industry at least indirectly but is vague. For example, we wish to be the best restaurant or we wish to be the top selling restaurant in the world or more specifically such as to becoming renown throughout the United States as providing the most nutritious and healthy Mexican food options.

2. Futuristic - Forward looking, indicates the firm's aspirations over the next several years. 1) Statement provides little to no wording that could be judged futuristic in nature. For example, We conserve resources and make people happy. 2) provides at least some inclination of the future concern our outlook. For example, At ACME company we will continue to provide our customers automotive and home insurance needs and adapt as needed. 3) provides a more detailed inclination of the future concern for the firm.

3. Concise - Vision statements should only be a few words in length, shorter is better, and around one sentence in length. A total word count was utilized here.

4. Unique - What does the firm specialize in, what is the firm's competitive advantage, what makes the firm different from rivals. 1) The firm's vision statement includes no mention of its uniqueness or competitive advantage, for example, our vision is bringing smiles around the world 2) The firm's vision statement has words that may discuss uniqueness, competitive advantage however they are vague and at best only limit some possible industries from likely using the exact same vision statement yet still broad enough that many business in differing industries could use the same statement. For example, quality is what drives our success and remains our vision. 3) The firm's vision statement is specific enough that only firms in the same industry or sector could reasonably use the exact same statement. For example, We strive to become the premier compounding drug firm in the world, matching drugs to specific individual needs rather than a one drug fits all approach.

5. Inspiring - deriving from CEO Mack and others, motivates employees and customers to support the organization. 1) Only mentions being the best or profits, no mention of words that will inspire employees or customers to be great or support the firm for reasons other than growth or profit. For example, We want to be the top airline company in Europe. Or we care about customer and employee excellence in the food we sell or, we strive to produce the best wind turbines in the world. 2) Mentions words that can be viewed as inspiring but the overall statement is not specific and could be used for any firm in any industry. For example, we value relationships over profits or good ethics is good business 3) Mentions words that clearly inspire stakeholders to support the company for reasons other than mere utilitarian reasons. For example, We strive to produce the most efficient wind turbines in the world, leading to a cleaner earth and more efficient energy for generations to come.

\section{Mission Statement Coding Scheme}

Factors selected for analysis of the characteristics of mission statements include the following

1. Clear. Answers the question what business are we in and distinguishes the business from others. 1) Provides a mission but does not address the question what business are we in or addresses such that could be used for multiple firms in differing industries. For example, we help people from all around the world. 2) Answers the question what business we are in, but is not expanded upon and could be multiple businesses. For example, We are committed to serving fresh food. Here this could be any type of restaurant. 3) Clearly answers the questions what business we are in. For example, we are in the fast food business specializing in burgers and fries.

2. Broad in scope; does not include monetary amounts, numbers, percentages, ratios, or objectives. 1) Mission makes reference to both objectives and includes numbers, percentages, or ratios. 2) Mission makes reference to only objectives or includes numbers, percentages or ratios, but not both. 3) Mission does not include objectives or numbers, percentages or ratios.

3. Concise in nature. At total word count was used here. Generally around 100 words.

4. Inspiring - 1) Only mentions being the best or profits, no mention of words that will inspire employees or customers to be great or support the firm for reasons other than growth or profit. For example, We want to be the top airline company in Europe. Or we care about customer and employee excellence in the food we sell or, we strive to produce the best wind turbines in the world. 2) Mentions words that can be viewed as inspiring but the overall statement is not specific and could be used for any firm in any industry. For example, our vision is to put people first in everything we do. 3) Mentions words that clearly inspire stakeholders to support the company for reasons other than mere utilitarian reasons. For example, We strive to produce the most efficient wind turbines in the world, leading to a cleaner earth and more efficient energy for generations to come.

5. Written by describing products in a utilitarian nature. 1) No products or services are described 2) products or services are described but only referred to literally such as "railroads" or "pharmaceuticals" 3) Products and services are described but referred to in a utilitarian nature. For example, instead of railroads the word "transportation" is used or instead of pharmaceuticals the phrase "healthier world" is used.

\section{Cronbach Alpha Results}

Assessing Cronbach Alpha results, which is a measure to test interrater reliability results, were positive. Only one variable of the 8, "Vision Future" produced a questionable result below 0.70 in Figure 2 below. However, only one variable "Mission Clear" produced a good result over 0.80 . All variables but "Vision Future" were over 0.70 so reliability is to acceptable standards. Based on the reliability results, 8 
new variables were created in SPSS averaging the ratings of the two raters to create a composite score. This composite score was used in all subsequent analyses.

Table 2

\begin{tabular}{|l|l|}
\hline Vision Clear & 0.708 \\
\hline Vison Future & 0.618 \\
\hline Vision Unique & 0.753 \\
\hline Vision Inspiring & 0.772 \\
\hline Mission Clear & 0.813 \\
\hline Mission Broad & 0.733 \\
\hline Mission Utility & 0.732 \\
\hline Mission Inspiring & 0.762 \\
\hline
\end{tabular}

\section{RESULTS}

Hypothesis 1 was tested using a paired samples t-test in SPSS. The null was rejected in favor of the alternative with the average mission statement including approximately 33 words compared to the average vision statement containing 19 words. Significance level was at the 0.000 level and a $\mathrm{t}$-calculated value of 3.84. While there is no research to our knowledge that has tested vision and mission length, mission statements are generally thought of to be longer in length. Using the two-tailed test outlined above over a directional test, it is strongly supported statistically and practically that indeed mission statements are longer in length than vision statements.

Research by David et al., (2020) suggests that mission statements should be no longer than 100 words in length. For Hypothesis 2, testing the average word count for mission statements using 100 words as the test value the data was significant at the .000 level with average words of 33 are corresponding t-calculated value of -19 . These results suggest, in practice mission statements are generally statistically much shorter than theory suggests and one can comfortably argue practically shorter as well. The null hypothesis was not rejected in this case. New direction for writing mission statements can be updated to be shorter in length than previously thought.

Hypothesis 3 and Hypothesis 4 were examined to determine if the four new characteristics associated with vision statements were actually present. This research has never been empirically conducted before to our knowledge. A one sample t-test was performed with 1.0 used as the test statistic. Based on the coding scheme outlined earlier in the paper, a rating of 1 indicates the firm had a respective vision or mission statement however the characteristic was not present. Ratings of 2 indicate the characteristic was present while ratings of 3 indicate the characteristic was not only present but in addition was expanded upon. All 8 characteristics had scores ranging from 1.86 for average score (average rating of both raters) Mission Clear to 2.78 for average score Broad with their respective t calculated scores of 9.38 to 36.94 respectively. All $t$ calculated scores were significant at .000 . These results are compelling that Fortune 500 firms are including all four characteristics routinely in their vision statements and all four in their mission statements.

Figure 3 below reveals all characteristics for both mission and vision were statistically significant. Coupled with the high interrater reliability these findings are compelling for the first time providing an empirically tested framework for vision and mission statement characteristics in support of the alternative hypothesis for both Hypothesis 3 and Hypothesis 4.

Table 3

\begin{tabular}{|l|c|c|c|c|}
\hline Characteristic & $\mathrm{N}$ & Mean & T-Calculated & Significance \\
\hline Vision Clear & 74 & 1.87 & 9.94 & .000 \\
\hline Vision Future & 74 & 1.89 & 11.36 & .000 \\
\hline Vision Unique & 74 & 1.97 & 10.73 & .000 \\
\hline Vision Inspiring & 74 & 2.07 & 17.09 & .000 \\
\hline Mission Clear & 74 & 1.86 & 9.38 & .000 \\
\hline Mission Broad & 74 & 2.78 & 38.40 & .000 \\
\hline Mission Utility & 74 & 1.98 & 11.08 & .000 \\
\hline Mission Inspiring & 74 & 2.09 & 15.06 & .000 \\
\hline
\end{tabular}

Running regression analysis using the enter method in SPSS on the four mission characteristics, no significant results were found using ROE, ROA, Revenue, Profits, EPS, 10 year average EPS and 10 year total return average to shareholders as dependent variables. Likewise running the same analysis on the four vision statement characteristics no significant results to financial performance was found. Results here were conclusive that well written vision and mission statements had little effect on firm performance. These findings are in agreement with much of the previous literature but also in disagreement with some literature. There continues to be a debate on the correlation between vision and mission statements and firm performance. Our findings of no statistical correlation between financial measures and vision and mission characteristics is not to say vision and mission statements are not important or firms should not attempt to include components and characteristics in mission statements. Simply many other factors play into performance.

\section{New Contributions}

1. Determined needed characteristics of a vision and mission statement through examination of their association with organizational performance.

2. Determined characteristics which are commonly used in vision and mission statements.

3. Determined word count used in vision and mission statements.

4. Provided a framework for writing effective vision and mission statements based on characteristics commonly used by Fortune 500 firms. 


\section{CONCLUSIONS}

This article's purpose serves several areas to provide a comprehensive literature review on mission statement importance evolution in the literature which includes 1) provide a discussion on mission statement components and 2) provide a discussion on the link between mission statements and organizational performance whether performance be a traditional financial number or a more abstract factor such as customer satisfaction scores or employee commitment and 3) this paper's main contribution was to provide a set of characteristics commonly used in vision and mission statement construction. Despite the research on mission statements, very little research has been performed on vision statements, and no research has been performed to my knowledge examining clearly characteristics associated with both vision and mission statements.

\section{REFERENCES}

Alegre, I., Berbegal-Mirabent, J., Guerrero, A., \& Mas-Machuca, M. (2018). The real mission of the mission statement: A systematic review of the literature. Journal of Management \& Organization, 24(4), 456-473.

Bart, C. K., \& Baetz, M. C. (1998). The relationship between mission statements and firm performance: An explorator study. Journal of Management Studies, 36(6), 823-853.

Baetz, M.C. and Bart, C.K. (1996), "Developing mission statements which work", Long Range Planning, Vol. 29 No. 4, pp. 526-533. CrossRef | Google Scholar

Bart, C. K. (1996). High tech firms: Does mission matter? Journal of High Technology Management Research

David, F., \& David, F. (2020). Strategic Management Concept and Cases - A Competitive Advantage Approach (17 ed.). Essex: Pearson Education Limited. Pp. 1-636

David, F., \& David, F. (2017). Strategic Management Concept and Cases - A Competitive Advantage Approach (16 ed.). Essex: Pearson Education Limited. Pp. 1-651

David, Fred R., Forest R. David, and Meredith E. David. (2016). Benefits, characteristics, components, and examples of customeroriented mission statements. International Journal of Business, Marketing, and Decision Sciences (IJBMDS), 9(1): 19-32.

David, Meredith E, David, Forest R, and David, Fred R. (2014). Mission statement theory and practice: A content analysis and new direction. International Journal of Business, Marketing, and Decision Sciences (IJBMDS), 7(1): 95-109.

David, F.R. (1989), "How companies define their mission", Long Range Planning, Vol. 22 No. 1, pp. 90-97. CrossRef | Google Scholar
Dharmadasa, P., Maduraapeurma, Y., \& Kanthi Herath, S. (2012). Mission statements and compnay financial performance revisited. Internal Journal of Managerial and Financial Accounting, 314-322.

Desmidt, S., Prinzie, A. and Decramer, A. (2011), "Looking for the value of mission statements: a meta-analysis of 20 years of research", Management Decision, Vol. 49 No. 3, pp. 468-483.

DiMaggio, P. J., \& Powell, W. W. (1983). The iron cage revisited: Institutional isomorphism and collective rationality in organizational fields. American Sociological Review, 48, 147-160

Drucker, P. F. (1974). Management: Tasks, responsibilities and practices. New York, NY: Butterworth \& Heinemann.

Germain, and Cooper, B. (1990). How a Customer Mission Statement Affects Company Performance. Industrial Marketing Management, Vol. 19 Issue 1, p47-54. CrossRef | Google Scholar

George D and Mallery P (2003), SPSS for Windows Step by Step: A Simple Guide and Reference, Allyn \& Bacon, Boston.

Hirota, S., Kubo, K., Miyajima, H., Hong, P. and Park, Y.W. (2010), "Corporate mission, corporate policies and business outcomes: evidence from Japan”, Management Decision, Vol. 48 No. 7, pp. 1134-1153. CrossRef | Google Scholar

Jung, C. (2013). Organizational goal ambiguity and job satisfaction in the public sector. Journal of Public Administration Research and Theory.

Jung, C., \& Rainey, H. (2011). Organizational goal characteristics and pubic duty motivation in the US federal agencies. Review of Public Personnel Administration, 31(1), 28-47.

Klemm, M., Sanderson, S., \& Luffman, G. (1991). Mission statements: selling corporate values to employees. Long Range Planning, 24(3), 73-78. CrossRef | Google Scholar | PubMed

King R., \& Cleland (1979) Strategic Planning and Policy. 124.

Sidhu, J. (2003). Mission statements: Is it time to shelve them? European Management Journal (21), 439-446.

Spector P (1992), Summated Rating Scale Construction: An Introduction, Sage, Newburg Park, CA.

Pearce, J.A. and David, F. (1987), “Corporate mission statements: the bottom line", Academy of Management Executive, Vol. 1 No. 2, pp. 109-116. Google Scholar

Peyrefitte, Joe and David, Forest R. (2006). A content analysis of the mission statements of United States firms in four industries. International Journal of Management, 23 (2): 296-301. 
Peyrefitte (2012). The Relationship Between Stakeholder Communication in Mission Statements and Shareholder Value. Journal of Leadership, Accountability and Ethics. 28-40.

Vandijck, D and Desmidt, S. and Buelens, M. (2007). Relevance of Mission Statement in Flemish Not-For_Profit Healthcare Organizations. J Nurs Manag.131-141.

Williams R, Morrell D, and Mullane, J. (2015). Management Decision May 2014 446-459

2019 Fortune 500 June 2019, Fortune 500 